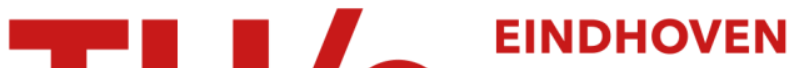 UNIVERSITY OF TECHNOLOGY
}

\section{A note on the wall singularity of a solid-liquid interface caused by a difference between the thermal conductivities of the solid and the liquid phases}

\section{Citation for published version (APA):}

Kuiken, H. K. (1988). A note on the wall singularity of a solid-liquid interface caused by a difference between the thermal conductivities of the solid and the liquid phases. SIAM Journal on Applied Mathematics, 48(4), 921-924. https://doi.org/10.1137/0148052

DOI:

$10.1137 / 0148052$

Document status and date:

Published: 01/01/1988

\section{Document Version:}

Publisher's PDF, also known as Version of Record (includes final page, issue and volume numbers)

\section{Please check the document version of this publication:}

- A submitted manuscript is the version of the article upon submission and before peer-review. There can be important differences between the submitted version and the official published version of record. People interested in the research are advised to contact the author for the final version of the publication, or visit the DOI to the publisher's website.

- The final author version and the galley proof are versions of the publication after peer review.

- The final published version features the final layout of the paper including the volume, issue and page numbers.

Link to publication

\footnotetext{
General rights

- You may freely distribute the URL identifying the publication in the public portal. follow below link for the End User Agreement:

www.tue.nl/taverne

\section{Take down policy}

If you believe that this document breaches copyright please contact us at:

openaccess@tue.nl

providing details and we will investigate your claim.
}

Copyright and moral rights for the publications made accessible in the public portal are retained by the authors and/or other copyright owners and it is a condition of accessing publications that users recognise and abide by the legal requirements associated with these rights.

- Users may download and print one copy of any publication from the public portal for the purpose of private study or research.

- You may not further distribute the material or use it for any profit-making activity or commercial gain

If the publication is distributed under the terms of Article $25 \mathrm{fa}$ of the Dutch Copyright Act, indicated by the "Taverne" license above, please 


\title{
A NOTE ON THE WALL SINGULARITY OF A SOLID-LIQUID INTERFACE CAUSED BY A DIFFERENCE BETWEEN THE THERMAL CONDUCTIVITIES OF THE SOLID AND THE LIQUID PHASES*
}

\author{
H. K. KUIKEN†
}

\begin{abstract}
In crystal-growth systems of the Bridgman-Stockbarger type, the solid-liquid interface touches a conducting wall which is the inner wall of the crucible. When the thermal conductivities of the solid and the liquid phases are different, which they usually are, the gradient of the axial thermal profile changes abruptly at the $s-1$ interface. Since the thermal profile in the adjacent crucible cannot experience such a jump, the $s-1$ interface must accommodate for this difference in thermal behavior at the wall. Using a fairly simple model example, we show that the $s-1$ interface becomes singular there. The singularity is a weak logarithmic one.
\end{abstract}

Key words. crystal growth, solid-liquid interface, Bridgman system, heat transfer, singularity

AMS(MOS) subject classifications. $35 \mathrm{~J} 05,41 \mathrm{~A} 60,80 \mathrm{~A} 20$

1. Introduction. In the crystal-growth literature some authors [1], [2], [3] have recently pointed to an interesting phenomenon that they conveniently refer to as the "interface effect." This effect occurs when a crystal is grown within the confines of a hot crucible by means of the so-called Bridgman technique. Owing to an abrupt change of thermal conductivities across the solid-liquid interface, the slopes of temperature profiles show a corresponding sudden change. This would seem to create a problem at the location where the interface meets the wall of the crucible. Indeed, as the crucible consists of material that can be thought of as homogeneous, temperature profiles are expected not to show a sudden variation of their slopes there. This creates the aforementioned interface effect.

The very few theoretical analyses [2], [3] that have been done in an attempt to understand this phenomenon have employed the so-called fin approach. In this approach simplified assumptions are made about the dependence of the temperature on one of the coordinates, usually the radial one, and an averaging technique is used to derive suitable field equations. Clearly, using such an approach we may only hope to get some insight into the global properties of the temperature field. It would not seem possible for the method to shed any light upon the finer aspects of the problem. Another recent paper [4] presents an investigation into the shape of the solid-liquid interface for a given wall heating, but it does not pay specific attention to the shape of the profile near the wall.

It would seem obvious to anyone of an applied-mathematical turn of mind that the way in which nature, as it is simulated by the usual equations and boundary conditions appertaining to heat transfer, will resolve the conflict described above is by creating a singularity. It is the purpose of this note to investigate and discuss the nature of this singularity. Since the problem involving conjugate heat conduction in a system consisting of a crucible containing material that is partly solid and partly liquid

* Received by the editors May 19, 1986; accepted for publication (in revised form) May 29, 1987. This work was carried out while the author was seconded to Philips Laboratories in Briarcliff Manor, New York 10510.

† Philips Laboratories, North American Philips Corporation, Briarcliff Manor, New York 10510. Present address, Philips Research Laboratories, 5600 JA Eindhoven, the Netherlands. 
may defy the analytical approach, we shall consider a simpler problem in which the temperature is prescribed at the outer boundary of the crystal. The melt is assumed to remain stationary. Furthermore, we shall restrict ourselves to a Cartesian geometry. Since the interface effect occurs at some distance from the crystal axis, and as we are interested only in what happens in the immediate vicinity of the singularity, there is no reason to consider the more complicated radial symmetry.

2. Analysis. Let us consider a slab of material of dimensionless thickness two. We use a Cartesian coordinate system $x, y$, where $y= \pm 1$ denote both faces of the slab. The coordinate $x$ measures distance along the slab. We consider stationary heat conduction so that

$$
\operatorname{div}(k \operatorname{grad} T)=0 \quad(-\infty<x<\infty,-1 \leqq y \leqq 1)
$$

where $k(T)$ is the thermal conductivity and $T$ the temperature (both dimensionless). At $T=0$ the material of the slab is assumed to melt or freeze. The influence of latent heat is disregarded.

A simple way to study the structure of the interface singularity is to consider the case where both walls are kept at a temperature $T=x$. In this case the interface touches the wall at $x=0$. Obviously, the unrealistic circumstance that $T \rightarrow-\infty$ if $x \rightarrow-\infty$ is not of importance here.

Although this problem is basically nonlinear, we may invoke the so-called Kirchhoff transformation [5] to convert it into a linear one. To that end we put

$$
Q=\int_{0}^{T} k d T .
$$

Since $k=k_{\text {solid }}=\gamma$ for $T<0$ and $k=k_{\text {melt }}=1$ for $T>0$, we obtain

$$
Q= \begin{cases}\gamma T & \text { for } T<0 \\ T & \text { for } T>0\end{cases}
$$

The problem is now recast in the following simple form:

$$
\begin{aligned}
& \Delta Q=0 \quad(-\infty<x<\infty,-1 \leqq y \leqq 1), \\
& Q=\left\{\begin{array}{ll}
\gamma x & (x<0) \\
x & (x>0)
\end{array} \quad(y= \pm 1) .\right.
\end{aligned}
$$

The solution to this problem can be expressed as follows:

$$
Q=x+\frac{1-\gamma}{\pi} \int_{x}^{\infty}\left(\frac{\pi}{2}-\arctan \left\{\frac{\sinh (\pi p / 2)}{\cos (\pi y / 2)}\right\}\right) d p .
$$

As we have said, the purpose of this contribution is to study the behavior of the curve $Q(x, y)=0$ in the vicinity of the point $(x, y)=(0,1)$, and similarly near $(0,-1)$, which is the same. Let us put therefore $y= \pm 1 \mp \eta$. This means that we must study the behavior of the integral

$$
I(x, M)=\int_{x}^{\infty}\left(\frac{\pi}{2}-\arctan \left\{M \sinh \left(\frac{\pi p}{2}\right)\right\}\right) d p
$$

for $|x| \ll 1$ and $M \gg 1$, where

$$
M=\frac{1}{\sin (\pi \eta / 2)}
$$


To evaluate the integral (8) asymptotically in the limits $M \rightarrow \infty$ and $|x| \rightarrow 0$, it is necessary to know the behavior of $M x$. If $M x \rightarrow \infty$, as will later turn out to be the case, it is easy to evaluate $I$ asymptotically. However, we do not know this beforehand. Therefore, we prefer to recast the integral in a different form that will enable us to deal with the double limit without having to make assumptions about the behavior of $M x$. To obtain the alternative form we differentiate (8) with respect to $M$. Evaluating the ensuing integral, and integrating that result with respect to $M$, we find:

$$
I=\frac{1}{\pi} \int_{M}^{\infty} \frac{1}{q\left(q^{2}-1\right)^{1 / 2}} \ln \left\{\frac{\cosh (\pi x / 2)+\left(q^{2}-1\right)^{1 / 2} / q}{\cosh (\pi x / 2)-\left(q^{2}-1\right)^{1 / 2} / q}\right\} d q-\pi x H(-x),
$$

where we have used $I \rightarrow 0$ when $M \rightarrow \infty$ for $x>0$ and $I \rightarrow-\pi x$ when $M \rightarrow \infty$ for $x<0$. Further, $H(x)$ is the unit step function.

Now we expand the integrand of (10) for $|x| \ll 1$ and $q \gg 1$. Retaining terms of the lowest order only, we have

$$
\begin{array}{r}
I \sim-\frac{1}{\pi} \int_{M}^{\infty} \frac{1}{q^{2}} \ln \left(\frac{\pi^{2} x^{2}}{16}+\frac{1}{4 q^{2}}\right) d q-\pi x H(-x) \\
+O\left(\frac{x^{2}}{M}\right)+O\left(\frac{\ln \left(\pi^{2} x^{2} / 16+1 / 4 M^{2}\right)}{M^{3}}\right) .
\end{array}
$$

Evaluating the integral, we obtain

$$
\begin{aligned}
I \sim \frac{1}{\pi}\{ & \left.-\frac{1}{M}+O\left(\frac{1}{M^{3}}\right)\right\} \ln \left(\frac{\pi^{2} x^{2}}{16}+\frac{1}{4 M^{2}}\right)+\frac{2}{\pi M}\left(1+O\left(x^{2}\right)\right) \\
& +x \arctan \left(\frac{\pi x M}{2}\right)-\frac{\pi}{2} x .
\end{aligned}
$$

Returning now to (9), we may convert (12) into asymptotics for $|x| \ll 1$ and $0 \leqq \eta \ll 1$. Finally, we may substitute the result in (7), whence we have

$$
\begin{aligned}
Q \sim x+\frac{1-\gamma}{\pi}\{ & -\frac{1}{2} \eta \ln \left(x^{2}+\eta^{2}\right)+\eta\left(1+\ln \frac{4}{\pi}\right) \\
& \left.+x \arctan \left(\frac{x}{\eta}\right)-\frac{\pi}{2} x\right\} \quad(|x| \ll 1,0 \leqq \eta \ll 1) .
\end{aligned}
$$

We are interested in the curve $Q(x, y)=0$. Let us put

$$
x=\eta g(\eta) \text {. }
$$

The curve is then described by

$$
\ln \eta \sim \frac{\pi}{1-\gamma} g-\frac{1}{2} \ln \left(1+g^{2}\right)+g \arctan (g)-\frac{\pi}{2} g+1+\ln \frac{4}{\pi} .
$$

Clearly, when $\eta \downarrow 0$, we must have $g \rightarrow \pm \infty$, the sign depending upon the value of $\gamma$. Let us assume first that $g \rightarrow \infty$. Then, expanding the logarithm and the arctangent for large values of $|g|$, we have

$$
\ln \eta \sim \frac{\pi}{1-\gamma} g-\ln g+\ln \frac{4}{\pi}+O\left(g^{-2}\right) .
$$

Since we assumed that $g \rightarrow \infty$, we have to require that $\gamma>1$. Inverting (16), we obtain

$$
g \sim \frac{1-\gamma}{\pi}\left\{\ln \eta+\ln \ln \frac{1}{\eta}+\ln \frac{\gamma-1}{4}\right\}+O\left(\frac{\ln |\ln \eta|}{\ln \eta}\right) .
$$


A similar expression may be derived for $0<\gamma<1$ and $g \rightarrow-\infty$. We now conclude that the solid-liquid interface reveals a weakly singular behavior near the point $(x, \eta)=$ $(0,0)$. The leading term of this singularity is given by

$$
x \sim \frac{1-\gamma}{\pi} \eta \ln \eta \quad(\gamma>1), \quad x \sim \frac{1-\gamma}{\pi \gamma} \eta \ln \eta \quad(\gamma<1) .
$$

As it approaches the wall, the solid-liquid interface curves towards the boundary in such a way that the tangent becomes parallel to the $x$-axis. In this way the system accommodates for the difference in thermal conductivities. It can also be seen that the solid-liquid interface is displaced in the direction of the phase that has the lowest thermal conductivity. We can show that this observation is also valid for values of $x$ and $y$ that are not close to either $(0,-1)$ or $(0,1)$.

Finally, it is tempting to think that it would have been much easier to demonstrate the singular behavior of (18) with a semi-infinite geometry, where $y \rightarrow \infty$ and with the boundary condition (6) defined at $y=0$. However, the solution to that problem is not unique, since we can always add $Q=(A x+B) y$ to any particular solution satisfying the boundary condition at $y=0$. The problem definition does not tell us how to select $A$ and $B$. It can be shown that $A$ affects the coefficient in (18). Since $A$ can be both positive and negative, the infinite problem does not settle the important question of the direction in which the interface is displaced depending upon whether $\gamma<1$ or $\gamma>1$.

Acknowledgments. I am indebted to Dr. M. Shone for drawing my attention to the interesting phenomenon discussed in this note.

It is a pleasure to acknowledge the pleasant atmosphere at Philips Laboratories in Briarcliff Manor, a fine facility within the Philips Worldwide research organization.

\section{REFERENCES}

[1] S. L. LEHOCZKY AND F. R. SzOFRAN, Directional solidification and characterization of $\mathrm{Hq}_{1-x} \mathrm{Cd}_{x} \mathrm{Te}$ alloys, in Materials Processing in the Reduced Gravity Environment of Space, G. E. Rindone, ed., North-Holland, Amsterdam, 1982, p. 409.

[2] T. JASINSKI AND A. F. WITT, Heat transfer of the Bridgman-Stockbarger configuration for crystal growth. II. Analytical treatment of rapid temperature variations, J. Crystal Growth, 67 (1984), pp. 173-184.

[3] - On control of the crystal-melt interface shape during growth in a vertical Bridgman configuration, J. Crystal Growth, 71 (1985), pp. 295-304.

[4] R. J. NAUMANN AND S. L. LEHOCZKY, Effect of variable thermal conductivity on isotherms in Bridgman growth, J. Crystal Growth, 61 (1983), pp. 707-710.

[5] J. Crank, Free and Moving Boundary Problems, Clarendon, Oxford, 1984. 